\title{
Novel Surgical Technique for Acoustic Transmitter Insertion in Rainbow Trout Reduces the Need for Surgical Training
}

\author{
Nathan Huysman ${ }^{1 *}$, Ashley Kelican ${ }^{1}$, Lauren Van Rysselberge ${ }^{1}$, Jeremy Kientz ${ }^{2}$, \\ Jill M. Voorhees ${ }^{1}$, Michael E. Barnes ${ }^{1}$
}

${ }^{1}$ South Dakota Department of Game, Fish and Parks, McNenny State Fish Hatchery, Spearfish, USA

${ }^{2}$ South Dakota Department of Game, Fish and Parks, Rapid City, USA

Email: *nathan.huysman@state.sd.us

How to cite this paper: Huysman, N., Kelican, A., Van Rysselberge, L., Kientz, J., Voorhees, J.M. and Barnes, M.E. (2021) Novel Surgical Technique for Acoustic Transmitter Insertion in Rainbow Trout Reduces the Need for Surgical Training. Advances in Bioscience and Biotechnology, 12, 275-285. https://doi.org/10.4236/abb.2021.129017

Received: August 11, 2021

Accepted: September 25, 2021

Published: September 28, 2021

Copyright $\odot 2021$ by author(s) and Scientific Research Publishing Inc. This work is licensed under the Creative Commons Attribution International License (CC BY 4.0).

http://creativecommons.org/licenses/by/4.0/

(c) (i) Open Access

\begin{abstract}
The implantation of acoustic transmitters into the peritoneal cavity of fish is typically performed by experienced surgeons. This study compared the effectiveness of an experienced and inexperienced surgeon performing two different types of transmitter insertion techniques on rainbow trout (Oncorhynchus mykiss). The methods used were either a traditional sutured ventral incision or a novel unsutured lateral incision. There was no significant difference in surgical duration, tag retention, or fish survival between the experienced and naive surgeon. The time to complete surgical wound closure was not significantly different between the fish operated on by an experienced or naïve surgeon, and surgeon experience had no significant effect on the duration of inflammation. However, there were significant differences between the two surgical techniques, regardless of surgeon experience. The ventral incision with sutures method took approximately three times longer to complete than the lateral incision-only method. However, complete wound closure was significantly faster in the sutured ventral incision treatment compared to the unsutured lateral treatment. Post-surgery inflammation was over seven times longer in the fish with sutures compared to those only receiving a lateral incision. Tag retention was not significantly different between the two surgical methods. The results of this study indicate that the unsutured lateral surgical technique used in this experiment can be completed with minimal training and surgical experience in contrast to the standard technique requiring sutures. These results also provide additional support to the use of sutureless surgical techniques for acoustic transmitter implantation.
\end{abstract}

\section{Keywords}

Surgery, Acoustic Transmitter, Rainbow Trout, Oncorhynchus mykiss 


\section{Introduction}

Traditionally, acoustic transmitters are inserted into the peritoneal cavity via an incision at or near the ventral midline, followed by one or more sutures for wound closure [1] [2]. However, two recent studies have documented the effectiveness of using non-suture surgical techniques during the implantation of acoustic transmitters. Huysman et al. [3] and Kelican et al. [4] used a small incision on either the ventral or lateral side of the fish without any form of wound closure; sutures were not used. This incision-only technique resulted in excellent tag retention and also decreased the redness and irritation associated with the use of sutures [3] [4] [5] [6].

Huysman et al. [3] suggested that these unsutured techniques may reduce the need for extensive training and experience to conduct implantation surgeries. Such training, including the possible supervision of a licensed veterinarian, has been strongly recommended for those individuals conducting acoustic transmitter implantation surgeries using established methods with sutures for wound closure [2] [7] [8] [9]. Cooke et al. [9] suggested a rigorous three-day training schedule combined with a final assessment was necessary for untrained professionals to acquire and master the skills necessary to complete fish surgeries. Differences in post-surgery survival and suture retention have been observed between expert and novice surgeons [10]. Deters et al. [8] even found a marked difference in surgical outcomes from a group of four highly trained surgeons.

Because the surgical techniques described by Huysman et al. [3] and Kelican et al. [4] are relatively simple and do not require suture training, it is possible that they could be successfully used by inexperienced individuals. However, there are no published studies examining this possibility. Thus, the objective of this study was to evaluate the effect of a novice surgeon using an unsutured technique on tag retention, wound closure, and inflammation in rainbow trout receiving acoustic transmitters.

\section{Materials and Methods}

This experiment was conducted at McNenny State Fish Hatchery, Spearfish, South Dakota, USA using well water $\left(11^{\circ} \mathrm{C}\right.$; total hardness as $\mathrm{CaCO}_{3}, 360 \mathrm{mg} / \mathrm{L}$; alkalinity as $\mathrm{CaCO}_{3}, 210 \mathrm{mg} / \mathrm{L}$; pH. 7.6; total dissolved solids, $390 \mathrm{mg} / \mathrm{L}$ ). Forty adult Shasta strain rainbow trout (mean (SE) initial length 334 (4) $\mathrm{mm}$ and weight $430(14) \mathrm{g}$ ) from a common pool were assigned to one of four treatments $(\mathrm{n}=10): 1$ ) sutured ventral incision by experienced surgeon; 2$)$ lateral unsutured incision by experienced surgeon; 3) sutured ventral incision by inexperienced surgeon; and 4) lateral unsutured incision by inexperienced surgeon. All fish were held in a flow-through rectangular raceway section $(4.7 \mathrm{~m}$ long $\times 2.4 \mathrm{~m}$ wide $\times 0.5 \mathrm{~m}$ deep) for the duration of the experiment.

\subsection{Surgical Procedures}

The inexperienced surgeon received approximately two hours of training on the 
traditional ventral surgical technique and suturing from an experienced surgeon prior to conducting the actual surgeries for the study. During training, the experienced surgeon demonstrated the proper mechanics of acoustic transmitter surgery and post-surgery wound care, along with providing feedback while the novice practiced incisions and suturing [8]. The inexperienced surgeon only received training on the traditional ventral method. No training was given on the novel lateral technique.

Each fish was anesthetized to stage 4 anesthesia [11] with $60 \mathrm{mg} / \mathrm{L}$ Tricaine Methanesulfonate (MS-222; Syndel Ferndale, Washington, USA) and weighed and measured (total length) to the nearest $\mathrm{g}$ and $\mathrm{mm}$. Then a unique visual implant tag (VI tag) $(1.2 \mathrm{~mm}, 2.7 \mathrm{~mm}$; Northwest Marine Ecology, Inc., Seattle, Washington, USA) was inserted behind the eye into the postorbital tissue for identification purposes [12]. Handling time to the nearest second was measured from when the fish were removed from the anesthetic water to when fish were placed into the raceway section after surgery.

The fish in the ventral sutured treatment were placed upside-down into a $\mathrm{v}$-shaped foam trough with their gills constantly irrigated with anesthetic water. A $10-\mathrm{mm}$ incision was made $3 \mathrm{~mm}$ from the mid-ventral line, anterior to the pelvic fins using an iodine-disinfected scalpel. Iodine disinfected inert acoustic transmitter $(9 \times 24 \mathrm{~mm}, 3.6 \mathrm{~g}$ weight in air, VEMCO, Bedford, Nova Scotia, Canada) was then inserted into the peritoneal cavity. The incisions were closed using two simple uninterrupted sutures (Oasis Monofilament absorbable sutures 4-0, Mettawa, Illinois, USA). Fish were then placed into the raceway section for recovery.

Fish in the novel lateral treatment were placed on their side on the foam pad and received a small, depth-controlled puncture/incision on their lateral side using an iodine-disinfected precision knife (X-ACTO, Elmer's Products, High Point, North Carolina, USA). The precision knife was measured off to a depth of $7 \mathrm{~mm}$, deep enough to open into the peritoneal cavity but shallow enough to prevent damage to any vital organs. The incision location was made on the lateral side of the fish, approximately $1 \mathrm{~cm}$ anterior to the pelvic fins and in-line with the pectoral fins. Forceps were used to open the wound wide enough to insert the inert acoustic transmitter. Fish received no wound closure method and were then allowed to recover in the raceway.

\subsection{Post-Surgery Rearing}

Fish were fed $4.5 \mathrm{~mm}$ floating extruded feed daily by hand to satiation (Oncor 80, Skretting USA, Tooele, Utah, USA). Dissolved oxygen levels were above 6 $\mathrm{mg} / \mathrm{L}$ throughout the course of the 12-week trial. Mean (SE) tag to body ratios were $0.91(0.04) \%$, well below the recommended $2 \%$ threshold [13].

\subsection{Post-Surgery Data Collection}

Every seven days, the fish were anesthetized, inspected for tag loss, measured to 
the nearest millimeter, and weighed to the nearest gram. The fish also had photographs taken of the surgical site for subsequent wound scoring. Each surgical site was graded by five different individuals to classify wound healing (closure) and inflammation (redness) of the wound sites using an adaptation of the Paukert et al. [14] method as described by Kientz et al. [15] (Table 1). At the end of the study, tag retention was verified by dissection.

The following formulas were used for analysis:

Tag retention $(\%)=100 \times($ initial number of fish tagged/final number retaining tags);

Gain = final weight - initial weight;

Specific Growth Rate $(S G R)=100 \times[($ Ln end weight - Ln start weight $) /$ number of days];

Condition Factor $(\mathrm{K})=10^{5} \times\left(\right.$ weight $/$ length $\left.{ }^{3}\right)$.

\subsection{Data Analysis}

Data were analyzed with the SPSS (24.0) statistical analysis program (IBM, Chicago, Illinois, USA) using One-way ANOVA and Tukey's HSD post hoc means comparison test. Significance was pre-determined at $p<0.05$. A Chi-square analysis $(p<0.05)$ was used to analyze tag retention among the treatments.

\section{Results}

There was no significant difference in handling (surgery) duration between the experienced and naïve surgeons (Table 2). However, there was a significant difference between surgical techniques, with the ventral incision with sutures method taking approximately three times longer to complete than the lateral incision only method. Tag retention followed a similar pattern, but there were no significant differences between the two levels of surgical experience or the two surgical methods (Table 3). Survival after surgery was not significantly different between the surgeons or technique. Only one fish died because of the surgery and tag implantation. During week three, one inexperienced ventrally-sutured fish died from surgical complications. Necropsy revealed that the surgical site had fused to the pyloric caeca. Three other fish from the experienced surgeon groups died on week five due to mammalian predation, two fish from the sutured ventral treatment and one fish from the lateral treatment.

Table 1. Scoring criteria for wound closure and wound redness severity were used to determine surgical wound healing for rainbow trout following dummy acoustic transmitter insertion surgery using two different surgical techniques with an experienced and an inexperienced surgeon.

\begin{tabular}{ccc}
\hline Score & Wound Closure & Wound Redness \\
\hline 0 & Complete Closure & No redness present \\
1 & Closure of $<50 \%$ & Redness localized to incision/suture site \\
2 & No closure & Redness extended beyond incision/suture site \\
\hline
\end{tabular}


Table 2. Mean (SE) handling time (seconds) of rainbow trout subjected to acoustic transmitter insertion surgery using two different surgical techniques with an experienced and an inexperienced surgeon. Means followed by a superscript letter are significantly different from each other $(p<0.05, \mathrm{~N}=10)$.

\begin{tabular}{cccc}
\hline & \multicolumn{2}{c}{ Experienced Surgeon } \\
\hline Incision Location & Sutured & Yes & No \\
\hline Ventral & Yes & $202(17) \mathrm{y}$ & $240(18) \mathrm{y}$ \\
Lateral & No & $76(9) \mathrm{z}$ & $70(8) \mathrm{z}$ \\
\hline
\end{tabular}

Table 3. Mean (SE) tag retention (\%) of rainbow trout subjected to acoustic transmitter insertion surgery using two different surgical techniques with an experienced and an inexperienced surgeon $(\mathrm{N}=8,9,9$, and 10 , for the experience surgeon ventral, experience lateral, inexperience surgeon ventral, and inexperience lateral, respectively).

\begin{tabular}{cccc}
\hline & \multicolumn{2}{c}{ Experienced Surgeon } \\
\hline Incision Location & Sutured & Yes & No \\
\hline Ventral & Yes & 63 & 63 \\
Lateral & No & 89 & 100 \\
\hline
\end{tabular}

At less than two weeks, wound closure to $50 \%$ was significantly quicker in the naïve surgeon sutured ventral incision group than any of the other treatments (Table 4). Closure to $50 \%$ was also significantly faster in both of the sutured ventral incision groups than the unsutured lateral treatments. Complete wound closure was significantly faster in ventral surgery treatments than the lateral method (Table 5), but there was no significant difference between the fish operated on by an experienced or naïve surgeon. Post-surgery inflammation was minimal and quickly disappeared in the lateral incision groups (Table 6). In contrast, the number of weeks of inflammation was over seven times longer in the fish with sutures. Surgeon experience had no significant effect on the duration of inflammation.

Visual inspection of the surgical sites for the experienced (Image 1) and inexperienced (Image 2) surgeons displayed similar healing patterns. Redness/irritation occurred along sutures, especially when sutures were retained. The incisions made by the naïve surgeon were frequently off-axis and variable in length. Sutures were frequently off-axis as well. Suture retention was $90 \%$ for the experienced surgeon compared to only $75 \%$ for the naïve surgeon. Only a single fish from the experienced surgeon lost both sutures; one suture was lost in week six and one in week nine. The naive surgeon had three fish lose sutures. One lost both sutures in week nine, another lost one suture on week one and one suture on week seven, and the third fish lost one suture on week one but retained the other throughout the trial. The off-axis sutures and incisions did not negatively affect healing, survival, or tag retention scored between surgeons.

There was no significant effect of either surgical experience or surgical technique on ending fish length, weight, condition factor, gain, or specific growth rate. 


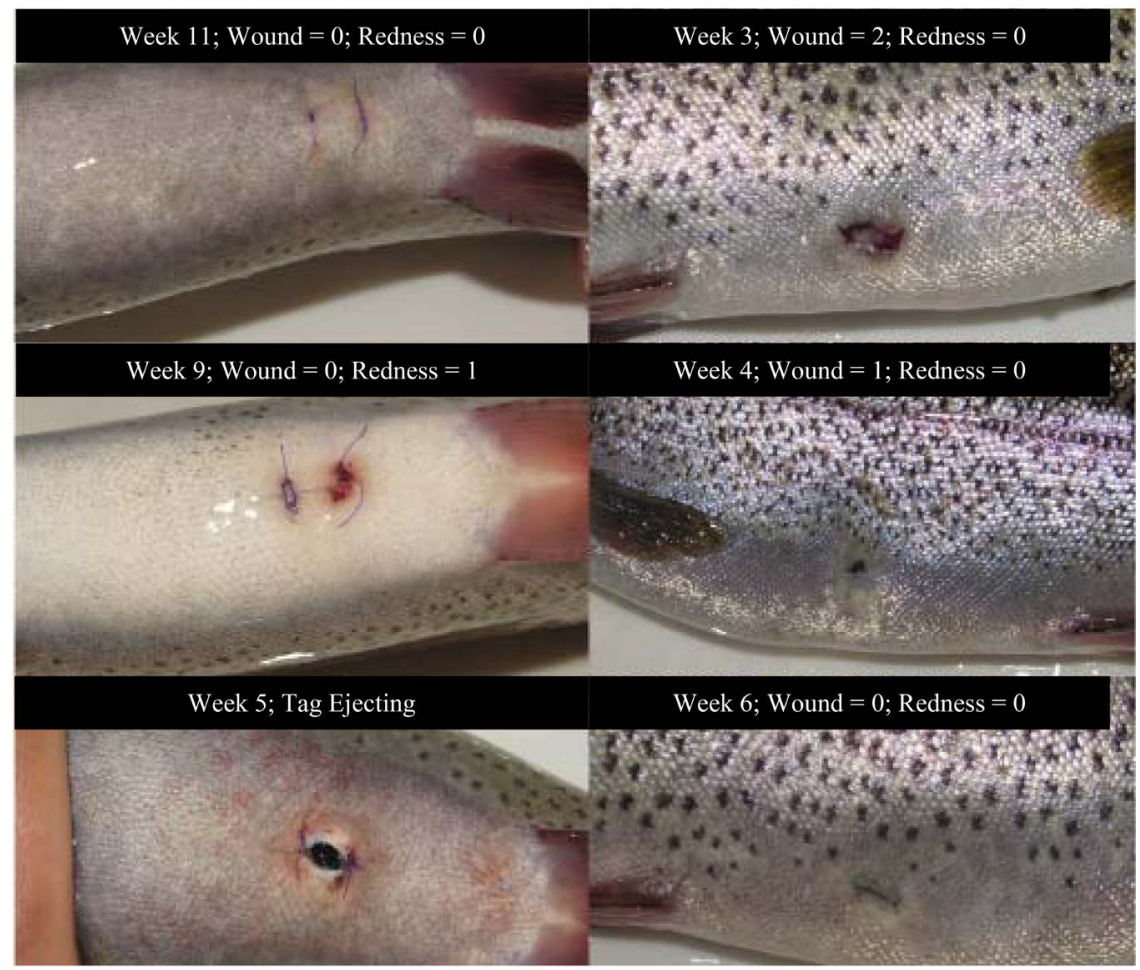

Image 1. Representative photographs of fish subjected to surgery by the experienced surgeon. The numbers on each photograph designate the wound closure and inflammation scores.

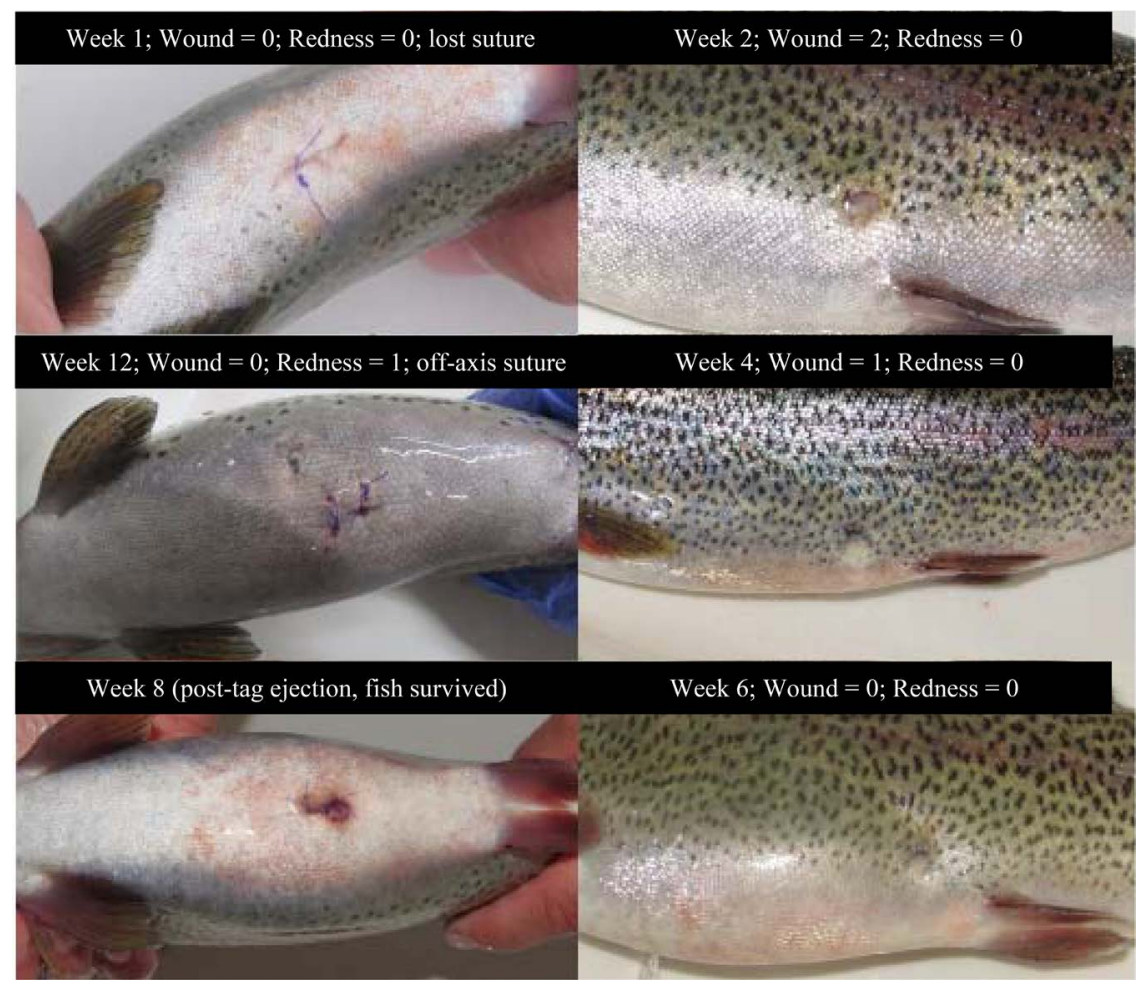

Image 2. Representative photographs of fish subjected to surgery by the inexperienced surgeon. The numbers on each photograph designate the wound closure and inflammation scores. 
Table 4. Mean (SE) weeks required for $50 \%$ wound closure for rainbow trout subjected to acoustic transmitter insertion surgery using two different surgical techniques with an experienced and an inexperienced surgeon. Means followed by a superscript letter are significantly different from each other $(p<0.05, \mathrm{~N}=8,9,9$, and 10 , for the experience surgeon ventral, experience lateral, inexperience surgeon ventral, and inexperience lateral, respectively).

\begin{tabular}{cccc}
\hline & & \multicolumn{2}{c}{ Experienced Surgeon } \\
\hline Incision Location & Sutured & Yes & No \\
\hline Ventral & Yes & $2.6(0.4) \mathrm{y}$ & $1.7(0.3) \mathrm{z}$ \\
Lateral & No & $4.5(0.2) \mathrm{x}$ & $3.8(0.2) \mathrm{x}$ \\
\hline
\end{tabular}

Table 5. Mean (SE) weeks required for complete wound closure for rainbow trout subjected to acoustic transmitter insertion surgery using two different surgical techniques with an experienced and an inexperienced surgeon. Means followed by a superscript letter are significantly different from each other $(p<0.05, \mathrm{~N}=8,9,9$, and 10 , for the experience surgeon ventral, experience lateral, inexperience surgeon ventral, and inexperience lateral, respectively).

\begin{tabular}{cccc}
\hline & \multicolumn{2}{c}{ Experienced Surgeon } \\
\hline Incision Location & Sutured & Yes & No \\
\hline Ventral & Yes & $4.5(0.4) \mathrm{z}$ & $3.9(0.4) \mathrm{z}$ \\
Lateral & No & $6.4(0.1) \mathrm{y}$ & $5.6(0.1) \mathrm{y}$ \\
\hline
\end{tabular}

Table 6. Mean (SE) weeks of post-surgery inflammation required for rainbow trout subjected to acoustic transmitter insertion surgery using two different surgical techniques with an experienced and an inexperienced surgeon. Means followed by a superscript letter are significantly different from each other $(p<0.05, \mathrm{~N}=8,9,9$, and 10 , for the experience surgeon ventral, experience lateral, inexperience surgeon ventral, and inexperience lateral, respectively).

\begin{tabular}{cccc}
\hline & & \multicolumn{2}{c}{ Experienced Surgeon } \\
\hline Incision Location & Sutured & Yes & No \\
\hline Ventral & Yes & $4.8(0.4) \mathrm{z}$ & $5.8(0.4) \mathrm{z}$ \\
Lateral & No & $0.1(0.1) \mathrm{y}$ & $0.7(0.2) \mathrm{y}$ \\
\hline
\end{tabular}

\section{Discussion}

The results of this study support the suggestion of Huysman et al. [3] that the novel, non-suture, lateral surgical technique can successfully be completed by a surgeon with minimal training or experience. It took the same amount of time for both the experienced and naive surgeon to complete the novel lateral surgery described by Huysman et al. [3] and Kelican et al. [4]. Thus, in addition to eliminating the inflammation caused by sutures, the incision-only technique is also beneficial because it eliminates the need for extensive surgical training.

With respect to traditional transmitter surgeries using ventral incisions and sutures, the results of this study also support the assertion of Deters et al. [8] that surgical feedback and surgeon aptitude may be essential for novice surgeons. 
While the novice surgeon in this trial did not receive an extensive training protocol [9], they did receive training that included direct feedback on proper wound apposition, suture tightness, and knot making [8].

Tag retention for the ventrally sutured groups was lower than observed in other studies using salmonids. Urbaniak et al. [5] and Kientz et al. [15] reported tag retention rates for ventrally sutured rainbow trout of $73 \%$ and $78 \%$ respectively. Bunnell and Isely [6] observed rainbow trout acoustic tag retention rates ranging from $73 \%$ to $88 \%$, depending on water temperature. Welch et al. [16] reported acoustic tag retention in trout of greater than $85 \%$. In contrast, higher tag retention rates of $89 \%$ and $100 \%$ in the unsutured lateral incision groups were observed in this study. These are similar to the $85 \%$ and $100 \%$ retention rates for brown trout Salmo trutta and rainbow trout reported by Huysman et al. [3] using the same unsutured lateral incision method.

The tag-to-body ratio of $0.91 \%$ used in this study was well below the recommended 2\% threshold [13] [16] [17] and should not have affected tag retention or other results. Tag retention can be negatively impacted by higher tag-to-body ratios [18] [19], although the $2 \%$ threshold has been successfully challenged many times [18] [19] [20] [21] [22].

Mulcahy [7] and Wargo Rub et al. [23] stated that implantation surgeries without sutures should rarely occur and must require justification. However, the results of this study, Huysman et al. [3], and Kelican et al. [4] clearly show the benefits of not using sutures during acoustic transmitter surgeries in rainbow trout at low tag-to-body ratios. In addition, better survival has been observed when Chinook salmon Oncorhynchus tshawytscha lost sutures [24]. Baras and Jeandrain [25] observed better tag retention in eel Anguilla anguilla when sutures were not used. Thus, further experimentation into the use of sutureless implantation techniques is justified.

This study was limited by using only one inexperienced surgeon. Deters et al. [8] found a difference among surgeons with perceivably the same amount of experience. Furthermore, this study only utilized large fish well over the $2 \%$ tag-to-body size recommendation. Further experimentation into the use of a lateral technique with other surgeons, different species of fish, and different size classes of fish is advised to determine the necessity of surgeon experience and training, as well as determine the efficacy of sutureless surgical transmitter implantation.

In conclusion, the unsutured lateral surgical technique used in this experiment can be completed with minimal training and surgical experience, in contrast to standard techniques requiring sutures. While these results may be specific to the species and size of fish used, they nonetheless provide additional support to the use of less irritating surgical techniques for acoustic transmitter insertion that do not use sutures.

\section{Acknowledgements}

We thank Eric Krebs, Tawnya Clees, and Jaid Freestone for with their assistance 
with this study.

\section{Conflicts of Interest}

The authors declare no conflicts of interest regarding the publication of this paper.

\section{References}

[1] Wargo Rub, A.M., Sandlord, B.P., Gilbreath, L.G., Meyers, M.S., Peterson, M.E., Charlton, L.L., Smith, S.G. and Matthews, G.M. (2012) Comparative Performance of Acoustic Tagged and Passive Integrated Transponder Tagged Juvenile Chinook Salmon in the Columbia and Snake Rivers, 2008. Fish Ecology Division, Northwest Fisheries Science Center, National Marine Fisheries Service, Seattle.

[2] Jepsen, N., Koed, A., Thorstad, E.B. and Baras, E. (2002) Surgical Implantation of Telemetry Transmitters in Fish: How Much Have We Learned. Hydrobiologia, 483, 239-248. https://doi.org/10.1023/A:1021356302311

[3] Huysman, N., White, S., Kientz, J., Voorhees, J.M. and Barnes, M.E. (2020) Suture-Less Implantation of Acoustic Transmitters in Two Salmonids. International Journal of Sciences, 9, 60-64. https://doi.org/10.18483/ijSci.2304

[4] Kelican, A.N., Huysman, N., VanRyssleberge, L., Voorhees, J.M. and Barnes, M.E. (2021) Assessment of a Novel Surgical Technique for Acoustic Transmitter Insertion. Open Journal of Veterinary Medicine, 11, 247-257. https://doi.org/10.4236/ojvm.2021.117016

[5] Urbaniak, T.J., Barnes, M.E. and Davis J.L. (2016) Acoustic Transmitters Impact Rainbow Trout Growth in a Competitive Environment. The Open Fish Science Journal, 9, 37-44. https://doi.org/10.2174/1874401X01609010037

[6] Bunnell, D.B. and Isely, J.J. (1999) Influence of Temperature on Mortality and Retention of Simulated Transmitters in Rainbow Trout. North American Journal of Fisheries Management, 19, 152-154. https://doi.org/10.1577/1548-8675(1999)019<0152:IOTOMA>2.0.CO;2

[7] Mulcahy, D.M. (2003) Surgical Implantation of Transmitters into Fish. ILAR Journal, 44, 295-306. https://doi.org/10.1093/ilar.44.4.295

[8] Deters, K.A., Brown, R.S., Carter, K.M., Boyd, J.W., Eppard, M.B. and Seaburg, A.G. (2010) Performance Assessment of Suture Type, Water Temperature, and Surgeon Skill in Juvenile Chinook Salmon Surgically Implanted with Acoustic Transmitters. Transactions of the American Fisheries Society, 139, 888-899. https://doi.org/10.1577/T09-043.1

[9] Cooke S.J., Wagner, G.N., Brown, R.S. and Deters, K.A. (2011) Training Considerations for the Intracoelomic Implantation of Electronic Tags in Fish with a Summary of Common Surgical Errors. Reviews in Fish Biology and Fisheries, 21, 11-24. https://doi.org/10.1007/s11160-010-9184-4

[10] Cooke S.J., Graeb B.D.S., Suski, C.D. and Ostrand, K.G. (2003) Effects of Suture Material on Incision Healing, Growth and Survival of Juvenile Largemouth Bass Implanted with Miniature Radio Transmitters: Case Study of a Novice and Experienced Fish Surgeon. Journal of Fish Biology, 62, 1366-1380. https://doi.org/10.1046/j.1095-8649.2003.00119.x

[11] Hikasa Y., Takase, K., Ogasawara, T. and Ogasawara, S. (1986) Anesthesia and Recovery with Tricaine Methanesulfonate, Eugenol and Thiopental Sodium in the Carp, Cyprinus carpio. Japanese Journal of Veterinary Science, 48, 431-351. 
https://doi.org/10.1292/jvms1939.48.341

[12] Davis, J.L., Barnes, M.E., Kientz, J.L. and Galinat, A.G. (2014) Effects of Fish Length and Anatomical Placement on Retention of Visible Implant Alpha Tags in Hatchery-Reared Rainbow Trout. North American Journal of Fisheries Management, 34, 932-937. https://doi.org/10.1080/02755947.2014.932868

[13] Winter, J.D. (1996) Advances in Underwater Biotelemetry. In: Murphy, B.R. and Willis, D.W., Eds., Fisheries Techniques, 2nd Edition, American Fisheries Society, Bethesda, 555-590.

[14] Paukert, C.P., Chavala, P.J., Heikes B.L. and Brown, M.L. (2001) Effects of Implanted Transmitter Size and Surgery on Survival, Growth, and Wound Healing of Bluegill. Transactions of the American Fisheries Society, 125, 707-714.

[15] Kientz, J., Huysman, N. and Barnes, M.E. (2020) A Comparison of Cyanoacrylate to Sutures for Wound Closure Following Acoustic Transmitter Insertion in Rainbow Trout. Aquaculture and Fisheries, 6, 513-518. https://doi.org/10.1016/j.aaf.2020.07.014

[16] Welch, D.W., Batten, S.D. and Ward, B.R. (2007) Growth, Survival, and Tag Retention of Steelhead Trout (O. mykiss) Surgically Implanted with Dummy Acoustic Tags. Hydrobiologia, 582, 289-299. https://doi.org/10.1007/s10750-006-0553-x

[17] Jepsen, N., Schreck, C., Clements, S. and Thorstad, E.B. (2005) A Brief Discussion of the $2 \%$ Tag/Bodymass Rule of Thumb. In: Spedicato, M.T., Lembo, G. and Marmulla, G., Eds., Aquatic Telemetry: Advances and Applications, FAO/COISPA, Rome, 225-260.

[18] Rechisky, E.L. and Welch, D.W. (2009) Surgical Implantation of Acoustic Tags: Influence of Tag Loss and Tag-Induced Mortality on Free Ranging and Hatchery-Held Spring Chinook (O. tschawytscha) Smolts. In: PNAMP Special Publication: Tagging, Telemetry and Marking Measures for Monitoring Fish Populations-A Compendium of New and Recent Science for Use in Informing Technique and Decision Modalities, Pacific Northwest Aquatic Monitoring Partnership, 1-96.

[19] Smircich, M.G. and Kelly, J.T. (2014) Extending the 2\% Rule: The Effects of Heavy Internal Tags on Stress Physiology, Swimming Performance, and Growth in Brook Trout. Animal Biotelemetry, 2, Article No. 16.

https://doi.org/10.1186/2050-3385-2-16

[20] Brown, R.S., Cooke, S.J., Anderson, W.G. and McKinley, R.S. (1999) Evidence to Challenge the "2\%" Rule for Biotelemetry. North American Journal of Fisheries Management, 19, 867-871. https://doi.org/10.1577/1548-8675(1999)019<0867:ETCTRF>2.0.CO;2

[21] Chittenden, C.M., Butterworth, K.G., Cubitt, K.F., Jacobs, M.C., Ladouceur, A., Welch, D.W. and McKinley, R.S. (2009) Maximum Tag to Body Size Ratios for an Endangered Coho Salmon (O. kisutch) Stock Based on Physiology and Performance. Environmental Biology of Fishes, 84, 129-140. https://doi.org/10.1007/s10641-008-9396-9

[22] Klinard, N.V., Halfyard, E.A., Fisk, A.T., Stewart, T.J. and Johnson, T.B. (2018) Effects of Surgically Implanted Acoustic Tags on Body Condition, Growth, and Survival in a Small, Laterally Compressed Forage Fish. Transactions of the American Fisheries Society, 147, 749-757. https://doi.org/10.1002/tafs.10064

[23] Wargo Rub, A.M., Jepsen, N., Liedtke, T.L., Moser, M.L. and Scott Weber III, E.P. (2014) Surgical Insertion of Transmitters and Telemetry Methods in Fisheries Research. American Journal of Veterinary Research, 75, 402-416.

https://doi.org/10.2460/ajvr.75.4.402 
[24] Wargo Rub, A.M., Sandlord, B.P., Gilbreath, L.G., Meyers, M.S., Peterson, M.E., Charlton, L.L., Smith, S.G. and Matthews, G.M. (2011) Comparative Performance of Acoustic Tagged and Passive Integrated Transponder Tagged Juvenile Chinook Salmon in the Columbia and Snake Rivers, 2008. National Oceanic and Atmospheric Administration, Seattle.

https://www.webapps.nwfsc.noaa.gov/assets/26/6821_03282014_103756_Rub.et.al.2 011-accessible.pdf

[25] Baras, E. and Jeandrain, D. (1998) Evaluation of Surgery Procedures for Tagging Eel Anguilla anguilla (L.) with Biotelemetry Transmitters. Hyrdobiologia, 371-372, 107-111. https://doi.org/10.1023/A:1017090117425 